\title{
Dietary lipids and vascular function: UK Food Standards Agency workshop report
}

\author{
Peter Sanderson ${ }^{1 *}$, Margreet Olthof ${ }^{2}$, Robert F. Grimble ${ }^{3}$, Philip C. Calder ${ }^{3}$, Bruce A. Griffin ${ }^{4}$, \\ Nicole M. de Roos ${ }^{5}$, Jill J. F. Belch ${ }^{6}$, David P. R. Muller ${ }^{7}$ and Joseph A. Vita ${ }^{8}$ \\ ${ }^{1}$ Nutrition Division, Food Standards Agency, London, UK \\ ${ }^{2}$ Wageningen Centre for Food Sciences, Human Nutrition and Epidemiology, Wageningen, The Netherlands \\ ${ }^{3}$ Institute of Human Nutrition, School of Medicine, University of Southampton, Southampton, Hants., UK \\ ${ }^{4}$ Centre for Nutrition and Food Safety, School of Biomedical and Life Sciences, University of Surrey, Guildford, \\ Surrey, UK \\ ${ }^{5}$ UMC Utrecht, Division of Dietetics, Utrecht, The Netherlands \\ ${ }^{6}$ Vascular Diseases Research Unit, Department of Medicine, Ninewells Hospital and Medical School, Dundee, UK \\ ${ }^{7}$ Institute of Child Health, London, UK \\ ${ }^{8}$ Section of Cardiology, Boston Medical Center, Boston, MA, USA
}

(Received 3 September 2003 - Accepted 29 September 2003)

The UK Food Standards Agency convened a group of expert scientists to review current research investigating the effect of dietary lipids on vascular function. The workshop highlighted the need for intervention studies to be sufficiently powered for these measures and that they should be corroborated with other, more validated, risk factors for CVD. Work presented at the workshop suggested a beneficial effect of long-chain $n$-3 PUFA and a detrimental effect of trans fatty acids. The workshop also considered the importance of the choice of study population in dietary intervention studies and that 'at risk' subgroups within the general population may be more appropriate than subjects that are unrepresentatively healthy.

Vascular function: Dietary lipids: $\boldsymbol{n - 3}$ Polyunsaturated fatty acids: Fish oils: trans Fatty acids: Saturated fatty acids: Food Standards Agency

On 3 March 2003, the UK Food Standards Agency (FSA) convened a workshop on the use of measures of vascular function in dietary intervention studies and the effect of dietary lipids upon them. The results from recently completed studies (both FSA and non-FSA funded) were presented, and the workshop was chaired by Professor Joseph Vita (Boston University). The aim of the workshop was to determine where this work has taken us and where further work should be concentrated, as well as acting as a vehicle for dissemination. The research recommendations will feed into the future direction of FSA-funded nutrition research, and may also be of value in guiding other funders.

The vascular endothelium is an active tissue and possesses numerous anti-atherogenic functions in a normal healthy state. These include regulation of blood flow in response to metabolic demands, inhibition of blood clotting and prevention of inflammatory cell adhesion to and subsequent migration through the endothelium. Endothelial 'dysfunction' can be considered to be present when the properties of the endothelium, either in a basal state or after stimulation, have altered in a way that is inappropriate with regard to preservation of normal function. Endothelial dysfunction is characterised by an alteration in phenotype, including decreased bioavailability of $\mathrm{NO}$, a shift in the relative balance of pro- and anticoagulant factors, and increased expression of pro-inflammatory molecules. These changes may increase the risk for vasoconstriction, thrombosis, vascular inflammation and plaque activation, the processes that contribute to the development and clinical expression of CVD. Impaired endothelium-dependent vasodilation has emerged as a readily measurable endothelial response that appears to correlate with a number of diverse endothelial functions.

Evidence that endothelial dysfunction contributes to the atherogenic process is provided by clinical studies showing impaired vasodilator responses in patients with CVD risk factors. These abnormalities are often present before the development of clinically or angiographically evident atherosclerosis. For example, classical risk factors 
including advancing age, dyslipidaemia, hypertension, diabetes mellitus and cigarette smoking have been associated with impaired endothelium-dependent vasodilation. Similarly, endothelial dysfunction has been reported in the setting of novel risk factors, such as hyperhomocysteinaemia, elevated lipoprotein(a) concentration, obesity, insulin resistance and systemic inflammation and/or infection. Patients with advanced atherosclerosis also display endothelial dysfunction. Further evidence for the relevance of endothelial dysfunction is provided by the observation that diverse therapies proven to reduce cardiovascular risk also have the ability to improve endothelial function. Thus, lipid-lowering therapy, angiotensin-converting enzyme inhibitors, smoking cessation and exercise all improve endothelial function and reduce cardiovascular risk. On the basis of these studies, endothelial function has been proposed as a clinically useful barometer of the combined impact of risk factors on vascular health (Vita \& Keaney, 2002).

The strongest evidence for the clinical importance of endothelial function is provided by prospective studies that demonstrate the prognostic value of endothelial dysfunction for CVD. This issue has been investigated in patients with established atherosclerosis (Neunteufl et al. 2000; Schächinger et al. 2000; Suwaidi et al. 2000; Heitzer et al. 2001; Gokce et al. 2002, 2003; Halcox et al. 2002) and in subjects with elevated CVD risk factors (Perticone et al. 2001; Modena et al. 2002; Schindler et al. 2003). To date, however, no study has specifically examined the question of whether reversing endothelial dysfunction can be equated with a reduction in cardiovascular risk. Such information is critical before endothelial function can be completely accepted as a true surrogate marker for cardiovascular risk.

\section{Measurement of vascular function}

A number of methods have been used to examine endothelial function. Most examine endothelium-dependent vasodilation. Vasodilator responses to endothelium-dependent stimuli have been examined in the coronary circulation using quantitative angiography, the forearm microcirculation using venous occlusion plethysmography, and the conduit brachial artery using high-resolution ultrasound (flow-mediated dilatation; FMD) (Vita, 2002). FMD involves a series of ultrasonographic measurements of blood vessel diameter and flow. A blood pressure cuff is then placed around the arm and inflated to a suprasystolic pressure for approximately $4 \mathrm{~min}$. On release of the cuff after $5 \mathrm{~min}$, reactive hyperaemia is induced and shear stress promotes endothelium-dependent vasorelaxation.

Alternatively, small vessel endothelial function can be measured by using the skin circulation as a surrogate marker of generalised microvascular endothelial function. In this process, vasoactive chemicals (e.g. acetylcholine (endothelium-dependent) and sodium nitroprusside (endothelium-independent)) can be delivered transdermally to the skin microvessels using a small electric current (iontophoresis). The subsequent microvascular response can be measured by laser Doppler imaging, which measures perfusion in the top $1.0-1.5 \mathrm{~mm}$ of skin. Although the prognostic value of small vessel endothelial function has yet to be demonstrated, changes in the microcirculation have been shown to parallel changes in the macrocirculation (Ramsay et al. 2002).

Arterial 'stiffness' measures (based on measurements of the material properties of the vessel wall or the capacitance function of the vessel as a whole) can also be assessed: pulse pressure, pulse wave analysis, pulse wave velocity, digital volume pulse and pulse contour analyses. This is a measure of the elasticity of the vessel (the relative volume change for a given pressure increment) and appears, in part, to depend on the vascular endothelium. Measures of arterial 'stiffness' have the advantage of being fast and simple and have been shown to have prognostic value for cardiovascular events (Boutouyrie et al. 2002; London \& Cohn, 2002; Safar et al. 2002).

Finally, circulating markers of endothelial function may be assessed in blood. In subjects without known CVD, soluble intracellular adhesion molecule-1 (Ridker et al. 1998) and tissue plasminogen activator (Thogersen et al. 1998) have been shown to predict future cardiovascular events. In patients with known CVD, soluble intracellular adhesion molecule-1 (Haim et al. 2002), von Willebrand factor (Thompson et al. 1995; Wiman et al. 2000), tissue plasminogen activator (Thompson et al. 1995) and plasminogen activator inhibitor-1 (Hamsten et al. 1987) are independent predictors of future events. These studies are consistent with studies suggesting that non-endothelium-derived markers of inflammation, such as C-reactive protein, identify high-risk individuals (Pearson et al. 2003).

Most recently, endothelial progenitor cells have been measured in blood and their function was shown to relate to risk factors and endothelium-dependent vasodilation (Hill et al. 2003). An important issue in this field is the lack of uniform standards for measurement of endothelium-dependent vasodilation or other aspects of endothelial function, and the lack of a consensus in regard to the best approach for specific types of study.

\section{Dietary factors}

The strength of evidence for dietary factors affecting endothelial function differs for differing dietary constituents. Replacement of a saturated fat-enriched diet with a highfat high-MUFA diet, but not a low-fat high-carbohydrate diet, was shown to improve FMD in hypercholesterolaemic patients (Fuentes et al. 2001); furthermore, in healthy subjects, a high-fat high-MUFA diet was also shown to decrease circulating markers of endothelial activation (plasminogen activator inhibitor-1, von Willebrand factor and tissue factor pathway inhibitor), whereas a low-fat high-carbohydrate or high-fat high-saturated fat diet did not (Perez-Jiminez et al. 1999). Other studies, however, have shown no difference in either FMD (de Roos et al. 2001 b) or arterial elasticity (Ashton et al. 2000) when comparing high-fat high-MUFA diets with low-fat high-carbohydrate diets in healthy subjects.

High doses of fish oils (4-5 g EPA + docosahexaenoic acid (DHA)/d) have been shown to improve FMD in hypercholesterolaemic subjects (Goodfellow et al. 2000), forearm blood flow in healthy subjects (Chin et al. 1993) 
and endothelium-dependent vasodilator responses to intracoronary acetylcholine infusion in heart-transplant recipients (Fleischhauer et al. 1993). Mori et al. (2000) demonstrated that DHA $(4 \mathrm{~g} / \mathrm{d})$, but not EPA $(4 \mathrm{~g} / \mathrm{d})$, enhanced forearm blood flow.

High doses of folic acid $(5-10 \mathrm{mg} / \mathrm{d})$ have also been shown to improve FMD in coronary-artery disease patients (Title et al. 2000; Doshi et al. 2001) and smokers (O'Grady et al. 2002), forearm blood flow, but not arterial elasticity, in smokers (Mangoni et al. 2002), and volumetric coronary blood flow in hyperhomocysteinaemic patients with coronary artery disease (Willems et al. 2002). This effect was shown to be independent of a plasma homocysteine-lowering effect (Doshi et al. 2002). Lower doses of folic acid (e.g. $0.4 \mathrm{mg} / \mathrm{d}$ ), which are attainable through the diet and result in maximal homocysteine reductions, have no effect on FMD (Pullin et al. 2001; Hirsch et al. 2002).

Flavonoid-rich beverages have been demonstrated to improve endothelial function with acute and long-term intake of flavonoid-containing beverages including tea (Duffy et al. 2001), grape juice (Stein et al. 1999) and de-alcoholised red wine (Agewall et al. 2000).

The results from studies investigating the effect of high doses of vitamin $\mathrm{E}$ (typically $\geq 590 \mathrm{mg} \alpha$-tocopherol/d) and vitamin $\mathrm{C}(\geq 1 \mathrm{~g} / \mathrm{d})$ on endothelial function are equivocal (for review, see Duffy et al. 1999). Although one study suggested that patients with multiple risk factors, particularly cigarette smoking, derive benefit from vitamin E supplementation (Heitzer et al. 1999), most other studies have failed to show a beneficial effect in patients with coronary artery disease or type 2 diabetes mellitus (Elliott et al. 1995; Chowienczyk et al. 1998; Gazis et al. 1999; Title et al. 2000). Studies of combinations of antioxidants, typically vitamin $\mathrm{C}$, vitamin $\mathrm{E}$ and $\beta$-carotene, have also provided disappointing results (Gilligan et al. 1994; MacKechnie et al. 2002). The findings with vitamin $\mathrm{E}$ and combination antioxidant therapy are consistent with large-scale clinical studies that demonstrated no benefit of antioxidant treatment on CHD (GISSI-Prevenzione Investigators, 1999; Yusuf et al. 2000; Heart Protection Study Collaborative Group, 2002).

A large number of studies have demonstrated a beneficial effect of acute, high-dose vitamin $\mathrm{C}$ (ascorbic acid) administration on endothelium-dependent vasodilation in patients with CVD and other disease states (Duffy et al. 1999). These studies provide insight into the pathophysiological mechanisms of vascular dysfunction and support a role of increased oxidative stress; however, the applicability of these studies to chronic vitamin $\mathrm{C}$ treatment on clinical endpoints remains uncertain.

It has been hypothesised that high-fat meals act as a trigger for acute coronary syndromes in populations with established atherosclerosis, by inducing a hypercoaguable and a vasoconstrictor state (Anderson et al. 2001). Several studies have demonstrated that high-fat meals, but not high-carbohydrate low-fat meals, induce acute impairment of FMD postprandially in healthy subjects (Plotnick et al. 1997, 2003; Vogel et al. 1997; Ong et al. 1999; Bae et al. 2001, 2003; Marchesi et al. 2000), diabetics (Fard et al. 2000) and, to a greater extent, patients with CHD (Ling et al. 2002). This impairment was attenuated by supplementing the test meal with either vitamins C $(1-2 \mathrm{~g})$ and $\mathrm{E}$ (590 mg) (Plotnick et al. 1997, 2003; Katz et al. 2001; Ling et al. 2002; Bae et al. 2003) or foods rich in these nutrients (fruits and vegetables concentrate (Plotnick et al. 2003), balsamic vinegar and salad (Vogel et al. 2000)). High-fat meals have also been shown to postprandially impair the coronary microcirculation (Hozumi et al. 2002), systemic arterial compliance (Nestel et al. 2001) and the rheologic response to L-arginine, which was attenuated by the addition of vegetables rich in vitamins $\mathrm{C}$ and $\mathrm{E}$ to the test meal (Esposito et al. 2003). Most studies also observed postprandial impairment of vascular function following a high-fat meal to be associated with postprandial hypertriacyglycerolaemia; as background diet has also been shown to affect the postprandial triacylglycerol response following a high-fat meal (Roche et al. 1998; Wolever \& Mehling, 2003) this may also be a factor.

Not all studies, however, have demonstrated postprandial impairment of FMD following a high-fat meal (Djousse et al. 1999; Raitakari et al. 2000; Gokce et al. 2001; Sejda et al. 2002). The reason for this discrepancy is unclear, and could be related to differences in the patient population studied or in the specific type of fat consumed. For example, Williams et al. (1999) demonstrated a meal high in oxidised fat, but not uncooked fat, impaired FMD; however, in a subsequent study no effect of heat modified fat was observed (Williams et al. 2001).

\section{Measure variability}

Dr Margreet Olthof presented results on studies investigating the variability in FMD of the brachial artery in young healthy subjects. The variability of FMD is large and this is important for the design of trials with FMD as an end point. The within-subject CV of the FMD measured off-line after images had been recorded on videotape (B-mode) is $50 \%$ (de Roos et al. 2003). In addition, the within-subject variability of the FMD measured with the wall-track method (M-mode) was determined: fourteen healthy, non-smoking subjects (seven men, seven women; age range 20-25 years) were measured on six occasions after an overnight fast.

The main findings from the study were:

- the mean FMD was $7 \cdot 8$ (SD 2.6) \% baseline diameter. Within-subject CV of FMD measured with the walltrack method was $46.4 \%$.

Thus, the within-subject variability of FMD measured with the wall-track method was similar to that of the B-mode. The consequences for the number of subjects needed in intervention trials is as follows: to detect a $2 \%$ difference in FMD (power 0.80, $\alpha$ 0.05), thirty to fifty subjects are needed in a crossover design, and sixty to one hundred subjects per group in a parallel design. Variability can be reduced by taking duplicate measurements. For Bmode ultrasound, duplicate reading of the videotapes is recommended, since the variation in reading of videotapes is large (CV $34 \%$; de Roos et al. 2003). The variation of $50 \%$ for single measurements was in accord with values obtained by other workers present. 


\section{Dietary modification of vascular function}

Dr Bruce Griffin presented preliminary findings (BA Griffin, MD Griffin, IR Davies, P Chowienczyk, GAA Ferns, DJ Millward and TAB Sanders, unpublished results) on indices of vascular function from an FSAfunded project (the OPTILIP study) that attempts to identify the optimum proportions of $\alpha$-linolenic and long-chain $n$-3 PUFA in the UK diet with regard to cardiovascular risk factors. Healthy middle-aged men and women (forty men, thirty women, aged 45-65 years) were randomised to diets: a control diet with an intake of $n-6$ and $n-3$ fatty acids similar to that in the UK diet; a diet enriched with long-chain n-3 PUFA; a diet enriched with a similar amount of $\alpha$-linolenic acid; a diet enriched with longchain $n$-3 PUFA and $\alpha$-linolenic acid; a diet with a more moderate $\alpha$-linolenic acid enrichment (the target $n-6: n-3$ fatty acid ratios were 10:1, 3:1, 3:1, 3:1 and 5:1 respectively). The dietary intervention period was 6 months.

FMD was measured in the brachial artery at rest and using a forearm occlusion cuff ( $5 \mathrm{~min}$; endothelium-dependent vasodilatation) and sublingual glycerol trinitrate (300 $\mu \mathrm{g}$ per tablet, $3 \mathrm{~min}$; endothelium-independent vasodilatation) to induce reactive hyperaemia. Arterial diameters were measured and averaged from four points in the twodimensional ultrasound image of the vessel wall at 30 , 90 and 180 s post-cuff, and 3.5 and 5.0 min after the administration of glycerol trinitrate ( 30 and 90 s post-glycerol trinitrate). FMD was assessed immediately before and after 6 months of dietary intervention.

These preliminary results suggest show no significant dietary effects on maximal FMD or pulse wave velocity; however, the duration of FMD may be less in subjects on $n-3$ fatty acid-rich diets. The clinical relevance of this finding, if confirmed, is unknown.

Dr Nicole de Roos presented the results of long-term and postprandial studies of saturated and trans fatty acids on vascular function. A high intake of trans fat increases the risk of CHD and some investigators believe that the effect of trans fatty acids is stronger than that of saturated fatty acids (Ascherio et al. 1999). The changes in serum cholesterol concentrations seen in metabolic studies after feeding trans fatty acids for a few weeks cannot fully explain the increased risk of CHD (Mensink \& Katan, 1992; Zock et al. 1995). Other effects, therefore, may contribute to the risk associated with high intakes of trans fats. All studies were performed in healthy volunteers between 18 and 70 years of age. The long-term dietary controlled study was performed in a crossover design with twenty-nine men and women (de Roos et al. 2001a), the postprandial study with twenty-one men (de Roos et al. 2002).

The main results were:

- replacement of $9.2 \%$ energy from saturated fatty acids by trans fatty acids significantly decreased serum HDLcholesterol after 4 weeks by $0.39 \mathrm{mmol} / 1$ (95\% CI 0.28 , 0.50 ) and impaired FMD from 6.2 to $4.4 \%$, a decrease of $1.8 \%$-points (95\% CI $0.4,3.2$ );

- this long-term adverse effect of trans fatty acids was not observed in the postprandial study: FMD after an oral fat load of $1 \mathrm{~g} / \mathrm{kg}$ bodyweight was 3.1 v. $2.6 \%$ before, with trans fatty acids and saturated fatty acids having similar effects.

This work suggests, therefore, that only long-term replacement of saturated fatty acids by trans fatty acids impairs vascular function. This may explain why trans fatty acids relate more strongly to risk of CVD than saturated fatty acids. The absence of an impairment in postprandial FMD was in contrast to some other, although not all, studies described in the literature.

Dr David Muller presented results from projects funded by the FSA, the Medical Research Council and the British Heart Foundation: they investigated the effects of genetic and other risk factors on the relationship between longchain n-3 PUFA, antioxidant status and vascular function (Leeson et al. 2002a,b,c). Increased fish consumption (resulting in increased $n-3$ PUFA consumption) and increased vitamin $\mathrm{E}$ intake are associated with a decreased risk of CVD, whereas a common variant of the endothelial NO synthase gene (Glu298Asp) has been shown to increase the risk of CVD (Shimasaki et al. 1998). These factors alone or in combination with each other and other known risk factors (e.g. smoking and blood lipids) have been related to measures of vascular function in early adulthood and thereby the development of CVD.

Endothelial function was assessed using FMD in 326 normal subjects aged 20-28 years. Arterial distensibility was also measured. These measures of vascular function were related to $n$-3 PUFA concentrations in plasma and erythrocyte membranes, plasma vitamin $\mathrm{E}$ concentrations and total antioxidant status, the genotype of the endothelial NO synthase glutamate-aspartate polymorphism, cardiovascular risk factors and diet.

The principal findings were:

- FMD was significantly reduced in smokers $(P<0.05)$ and there was a significant positive relationship between $n$-3 PUFA status and FMD in smokers $(P<0.01)$, which was not present in non-smokers (Leeson et al. 2002c);

- there were significant positive relationships between FMD and $n-3$ PUFA status in those subjects in the top one-third for fasting glucose, insulin and triacylglycerol levels with no relationships in those with lower levels (Leeson et al. 2002c);

- neither plasma vitamin E concentrations (alone or adjusted for lipid concentrations) nor total antioxidant status were related to any of the measures of vascular function (Leeson et al. 2002b);

- in the group as a whole, FMD was similar for the different endothelial NO synthase genotypes (Leeson et al. 2002a);

- there were no significant differences in FMD between smokers and non-smokers with the Glu/Glu genotype, whereas in subjects with Glu/Asp and Asp/Asp genotypes the smokers had a significantly reduced FMD $(P<0.01 ;$ Leeson et al. 2002a);

- there was a significant relationship between n-3 PUFA status and FMD in Glu/Asp and Asp/Asp subjects $(P<0.05)$, but not in those with the Glu/Glu genotype (Leeson et al. 2002a). 
These effects were seen with either DHA alone or DHA + EPA but not with EPA alone. The results show particularly: (1) the positive relationship between $n-3$ PUFA status and FMD in smokers and the subjects in the top one-third for fasting glucose, insulin and triacylglycerol levels; (2) the positive relationship between $n$-3 PUFA status and FMD in the endothelial NO synthase genotypes with an Asp allele, suggest the possibility of prevention strategies with increased n-3 PUFA intake targeted to specific groups at risk of CVD.

Professor Jill Belch presented results from two FSAfunded projects investigating the effects of dietary lipids on vascular function. In the first project (Khan et al. 2003), a total of 210 healthy subjects (men and women aged 40-65 years, non-smokers) were randomised to one of six groups ( $n$ 35) supplemented for 8 months with either $(\mathrm{g} / \mathrm{d})$ : placebo oil 10 , olive oil 10 , evening primrose (Oenothera biennis) oil $5+$ placebo oil 5 , soyabean oil $5+$ placebo oil 5 ; tuna oil 5 (0.30 g EPA, 1.35 g DHA) + placebo oil 5 , evening primrose oil $5+$ tuna oil 5 . The placebo oil comprised $250 \mathrm{~g}$ soyabean oil and $750 \mathrm{~g}$ fractionated coconut oil $/ \mathrm{kg}$; this was designed to reflect the average fatty acid composition of the Scottish diet.

Subjects were assessed for fatty acid status, biochemical and cellular markers of endothelial behaviour, haemostatic function and endothelial cell function and vascular tone, as determined by iontophoresis and laser Doppler imaging.

The main results were:

- tuna oil improved endothelial-dependent vascular responses; furthermore, there was a positive correlation between endothelial-dependent vascular responses and total plasma $n$-3 PUFA concentration;

- none of the other supplemented diets affected this measure of endothelial cell function;

- platelet aggregation was decreased after tuna oil + evening primrose oil and after olive-oil supplementation, but increased after evening primrose-oil supplementation.

These results suggests that fish-oil supplementation, at levels attainable through the diet, enhances both endothelial cell and platelet behaviour.

In the second study (JJF Belch, A Anderson, F Daly, J Dick, M McClaren, F Khan, A Hill and K Barton, unpublished results), 105 study healthy subjects (men and women, non-smokers, age $\geq 40$ years) were randomised, following a 1-month run-in, to one of three dietary groups ( $n$ 34): palmate, stearate or control. All subjects were maintained on their habitual total, saturated and unsaturated fat intakes. The intervention period lasted 4 months. The palmate and stearate groups received 50$60 \%$ total saturated fat intake $(6-10 \%$ total dietary energy) exchanged with either palmitic or stearic acid respectively. Professor Annie Anderson presented details of how this was achieved using margarines and biscuits of the appropriate saturated fat composition provided by Unilever (Vlaardingen, The Netherlands). Subjects were assessed for saturated fatty acid status, endothelial cell function and vascular tone (using iontophoresis and laser Doppler imaging), arterial compliance (pulse wave augmentation measured at the radial artery using applanation tonometry) and haemostatic function.

The main results were:

- no changes in any of the measures of vascular function were observed either before or after any of the dietary interventions;

- analysis of the biochemical and cellular markers showed no significant changes between the experimental groups and the control group. Analysis pre- and post-intervention, however, showed no significant changes in the control group, but the exchange that increased stearic acid seemed to produce what might be considered as beneficial changes, whereas the palmitic acid exchange did not. In the stearic group platelet NO production increased, P-selectin, E-selectin and fibrinogen levels fell, and in the palmitic acid group prothrombin time increased;

- in the palmitic acid group the proportion of oleic acid was decreased in the esterified forms of fatty acids present in plasma relative to the stearic acid and control groups.

In conclusion, therefore, in the first of these studies vasodilator changes were achieved in endothelial cell function with tuna-oil supplementation. In the second study, stearic acid appears to have some advantages over palmitic acid in terms of potential CV effects, but neither affected vascular function.

Professor Philip Calder presented results from an FSAfunded project investigating the association of $n-3$ PUFA with stability of advanced atherosclerotic plaques (Thies et al. 2003). Patients awaiting carotid endarterectomy were randomly assigned to consume placebo, sunfloweroil or fish-oil capsules until surgery, when the atherosclerotic plaque was removed ( $n>59$ per treatment group). Patients in the fish-oil group consumed an extra $1.4 \mathrm{~g}$ EPA and DHA/d. The fatty acid compositions of LDL and carotid plaque were determined. Plaques were classified morphologically. The presence of $\mathrm{T}$ lymphocytes and macrophages in the plaques was determined by immunohistochemistry. The mean duration of supplementation was 50 (range 7-189) d and did not differ between the groups.

The main results were:

- plasma triacylglycerol concentration was significantly decreased (mean decrease $28 \%$ ) in patients receiving fish oil;

- the proportions of EPA and DHA increased significantly in LDL-lipid fractions in patients receiving fish oil. The proportions of EPA and DHA were higher in carotid plaque phospholipids, cholesteryl esters and triacylglycerols in patients receiving fish oil compared with patients in the placebo group;

- in the fish-oil group, fewer plaques had thin fibrous caps and signs of inflammation and more plaques had thick fibrous caps and fewer signs of inflammation, compared with the other two groups;

- the number of macrophages in the plaques from patients receiving fish oil was lower than in the other two groups. 
This study shows that advanced atherosclerotic plaques are dynamic and readily incorporate $n-3$ PUFA. Incorporation of $n-3$ PUFA into carotid plaques is associated with a reduced number of macrophages and fewer signs of inflammation. These observations suggest that $n-3$ PUFA induce changes that may increase the stability of atherosclerotic plaques. If this is so, it represents a novel mechanism by which fish oil might prevent non-fatal and fatal cardiovascular events (for discussion, see Thies et al. 2003). The mechanism by which fish oil decreases the number of macrophages in plaques is not clear; it may involve decreased infiltration, increased loss (increased movement out of plaques or increased apoptosis) or a combination of such effects. The study did not investigate the activation state of the macrophages or the presence of inflammatory mediators within the plaques. These will be examined in a new study.

Professor Robert Grimble presented results from an extension of the previous FSA project to determine whether genetic variation in cytokine genes influences the effect of PUFA on atherosclerotic plaques (RF Grimble, WM Howell, PC Calder, CP Sheraman, P Gallagher, K Rekasem and $\mathrm{F}$ Thies, unpublished results). Inflammation plays a pivotal role in the development and stability of atherosclerotic plaques. Cytokines, key mediators of the inflammatory process, have been demonstrated to be present in atherosclerotic plaques (Ross, 1999). Individuals can be classed as habitually high-, medium-, or low-producers of certain cytokines (Jacob et al. 1990). Single nucleotide polymorphisms in cytokine genes, usually in the promoter region, result in altered levels of cytokine production, e.g. TNF- $\alpha$. Single nucleotide polymorphisms in pro-inflammatory cytokine genes have been linked with increased mortality during infection and after surgery (McGuire et al. 1994; Stuber et al. 1996) and with increased susceptibility to inflammatory disease (Schaaf et al. 2001). The ability of fish oil to exert an anti-inflammatory effect in healthy subjects, by suppression of TNF production, was influenced by the pre-supplementation level of cytokine production, and by single nucleotide polymorphisms at +252 in the TNF- $\beta$ gene (Grimble et al. 2002).

Preliminary studies indicate that:

- TNFB22 variant of the TNF- $\beta$ single nucleotide polymorphism may influence the soft lipid content of plaques;

- plaque characteristics, assessed according to the modified American Heart Association score, indicate that fish-oil supplementation results in plaques with a lower score in subjects possessing the TNF2 allele of the single nucleotide polymorphism in the TNF gene than patients homozygous for the TNF1 allele.

Thus, genotypes associated with a raised inflammatory status may be influenced to a greater extent by PUFA supplementation than those associated with a lower status. It should be noted, however, that due to the varying lengths of PUFA supplementation time and the absence of any effect on clinical end points, the results should be treated with some caution.

Currently, Biotechnology and Biological Sciences Research Council-funded studies are investigating the genomic nature of differing sensitivities of cytokine production to the anti-inflammatory influence of fish oil and vitamin E. Further work on gene nutrient influences on atherosclerosis requires clear demonstrations of clinical benefits resulting from nutritional intervention.

\section{Discussion}

Endothelial function appears to reflect the integrated effects of risk factors on the vasculature, and the development of endothelial dysfunction is an early event in the atherogenic process. Measures of endothelial function may provide a useful non-invasive methodology for assessing a clinically relevant surrogate end point; however, there is much methodological and physiological variability and this requires that studies are sufficiently powered in terms of sample size. Further, these issues make a crossover study design particularly useful.

Whether effecting a change in endothelial function results in a corresponding change in CVD risk remains to be determined. Measures of endothelial function, therefore, should be corroborated with other, more validated, risk factors for CVD, both conventional (fasting lipids, blood pressure, glucose concentration), and novel (high-sensitivity C-reactive protein, soluble intercellular adhesion molecule-1, von Willebrand factor, tissue plasminogen activator, plasminogen activator inhibitor-1), and measures of insulin sensitivity. As different study populations may display different risk factors, the choice of corroborating measures may depend on the specific study population.

Work presented at the workshop showed that in healthy subjects moderate fish-oil supplementation, at levels attainable through the diet, had a beneficial effect on endothelial function. Other ongoing FSA studies also address this issue and confirmation of an effect of dietary levels of $n-3$ PUFA on endothelial function will be important. In subjects at risk of CVD, higher circulating levels of DHA and EPA were associated with improved endothelial function. In patients awaiting carotid endartectomy, moderate fish-oil supplementation appeared to stabilise advanced atherosclerotic plaques making them less likely to rupture. Overall, these studies lend further support for population dietary recommendations to increase intake of oily fish. Other work presented showed that replacement of dietary saturated fatty acids with trans fatty acids impairs endothelial function and further supports population dietary recommendations to reduce trans fatty acid intake.

Another issue that was highlighted at the workshop is the choice of study population. The remit of FSA-funded research is not to study disease per se, but the impact of diet on the prevention of disease. The extrapolation of data from a disease population to a 'normal' population is difficult; however, if too many conditions of 'normality' are stipulated in the study inclusion criteria (e.g. blood pressure, BMI, plasma lipids) the study population can be unrepresentatively healthy: almost $30 \%$ of the English population have been diagnosed with some form of CVD (Department of Health, 1999). In addition, it is unlikely that relatively short-term interventions with modest changes in dietary intake can adequately mimic the effects of a lifetime exposure in individuals who are 'healthy'. 
Study populations exhibiting one or more risk factors for CVD, therefore, may be a more appropriate model and would also highlight vulnerable groups within the general population.

\section{Recommendations}

- Measures of endothelial function may provide a useful non-invasive methodology for assessing a clinically relevant surrogate endpoint, but at present such measures should be used in the context of studies that use other more traditional risk factors and other surrogate end points for CVD.

- For dietary intervention studies it is important to provide enough statistical power to account for both measure and physiological variation.

- The choice of study population in dietary intervention studies is important: 'at risk' subgroups within the general population may be more appropriate, e.g. as defined by CVD risk factors, genotype or lifestyle factors.

\section{Attendees}

Professor Joe Vita, Boston University; Professor Jill Belch and Professor Annie Anderson, Ninewells Hospital and Medical School, Dundee, Scotland, UK; Professor Bob Grimble, University of Southampton; Dr David Muller, Institute of Child Health, London, UK; Dr Naveed Sattar, University of Glasgow; Dr Nicole de Roos, University Medical Centre, Utrecht, The Netherlands; Professor Christine Williams, Dr James Latham, Dr Julie Lovegrove and Dr Chris Armah, University of Reading; Professor Tom Sanders, King's College, London; Dr Bruce Griffin, Dr Margaret Griffin, Professor Joe Millward and Professor Gordon Ferns, University of Surrey; Professor Philip Calder, University of Southampton; Dr Philip Chowienczyk, King's College, London; Dr Frank Thies, University of Aberdeen; Professor Rudolph Riemersma, University of Edinburgh; Professor Klaus Wahle, Rowett Research Institute, Aberdeen, Scotland, UK; Dr Margreet Olthof, Wageningen Centre for Food Sciences, Nutrition and Health Program, The Netherlands; Dr Judy Buttriss, British Nutrition Foundation, London, UK; Dr Richard Draijer and Dr Christine Kroner, Unilever Research, Vlaardingen, The Netherlands; Dr Ray Rice, International Society for the Study of Fatty Acids and Lipids, Tiverton, UK; Mr Ben Walters, Dr Alison Tedstone, Ms Mamta Singh and Dr Peter Sanderson, Food Standards Agency, London, UK.

\section{References}

Agewall S, Wright S, Doughty RN, Whalley GA, Duxbury M \& Sharpe N (2000) Does a glass of red wine improve endothelial function? Eur Heart J 21, 74-78.

Anderson RA, Jones CJ \& Goodfellow J (2001) Is the fatty meal a trigger for acute coronary syndromes? Atherosclerosis 159, $9-15$.

Ascherio A, Katan MB, Zock PL, Stampfer MJ \& Willett WC
(1999) Trans fatty acids and coronary heart disease. New Engl J Med 340, 1994-1998.

Ashton EL, Pomeroy S, Foster JE, Kaye RS, Nestel PJ \& Ball M (2000) Diet high in monounsaturated fat does not have a different effect on arterial elasticity than a low-fat, high-carbohydrate diet. J Am Diet Assoc 100, 537-542.

Bae JH, Bassenge E, Kim KB, et al. (2001) Postprandial hypertriglyceridemia impairs endothelial function by enhanced oxidant stress. Atherosclerosis 155, 517-523.

Bae JH, Schwemmer M, Lee IK, et al. (2003) Postprandial hypertriglyceridemia-induced endothelial dysfunction in healthy subjects is independent of lipid oxidation. Int $J$ Cardiol 87, 259-267.

Boutouyrie P, Tropeano AI, Asmar R, et al. (2002) Aortic stiffness is an independent predictor of primary coronary events in hypertensive patients: a longitudinal study. Hypertension 39, $10-15$.

Chin JP, Gust AP, Nestel PJ \& Dart AM (1993) Marine oils dosedependently inhibit vasoconstriction of forearm resistance vessels in humans. Hypertension 21, 22-28.

Chowienczyk PJ, Kneale BJ, Brett SE, Paganga G, Jenkins BS \& Ritter JM (1998) Lack of effect of vitamin E on L-arginine responsive endothelial dysfunction in patients with mild hypercholesterolemia and coronary artery disease. Clin Sci 94, 129-134.

de Roos NM, Bots ML \& Katan MB (2001a) Replacement of dietary saturated fatty acids by trans fatty acids lowers serum HDL cholesterol and impairs endothelial function in healthy men and women. Arterioscler Thromb Vasc Biol 21, $1233-1237$.

de Roos NM, Bots ML, Schouten EG \& Katan MB (2003) Within-subject variability of flow-mediated vasodilation of the brachial artery in healthy men and women: implications for experimental studies. Ultrasound Med Biol 29, 401-406.

de Roos NM, Bots ML, Siebelink E, Schouten E \& Katan MB (2001b) Flow-mediated vasodilation is not impaired when HDL-cholesterol is lowered by substituting carbohydrates for monounsaturated fat. Br J Nutr 86, 181-188.

de Roos NM, Siebelink E, Bots ML, van Tol A, Schouten EG \& Katan MB (2002) Trans monounsaturated fatty acids and saturated fatty acids have similar effects on postprandial flow-mediated vasodilation. Eur J Clin Nutr 56, 674-679.

Department of Health (1999) Health Survey for England. Cardiovascular Disease '98, London: H. M. Stationery Office.

Djousse L, Ellison RC, McLennan CE, et al. (1999) Acute effects of a high-fat meal with and without red wine on endothelial function in healthy subjects. Am J Cardiol 84, 660-664.

Doshi SN, McDowell IF, Moat SJ, et al. (2001) Folate improves endothelial function in coronary artery disease: an effect mediated by reduction of intracellular superoxide? Arterioscler Thromb Vasc Biol 21, 1196-1202.

Doshi SN, McDowell IF, Moat SJ, et al. (2002) Folic acid improves endothelial function in coronary artery disease via mechanisms largely independent of homocysteine lowering. Circulation 105, 22-26.

Duffy SJ, Keaney JF Jr, Holbrook M, et al. (2001) Short- and long-term black tea consumption reverses endothelial dysfunction in patients with coronary artery disease. Circulation 104, $151-156$.

Duffy SJ, Vita JA \& Keaney JF (1999) Antioxidants and endothelial function. Heart Fail 15, 135-152.

Elliott TG, Barth JD \& Mancini GBJ (1995) Effects of vitamin E on endothelial function in men after myocardial infarction. $A m$ $J$ Cardiol 76, 1188-1190.

Esposito K, Nappo F, Giugliano F, Giugliano G, Marfella R \& Giugliano D (2003) Effect of dietary antioxidants on postprandial 
endothelial dysfunction induced by a high-fat meal in healthy subjects. Am J Clin Nutr 77, 139-143.

Fard A, Tuck CH, Donis JA, et al. (2000) Acute elevations of plasma asymmetric dimethylarginine and impaired endothelial function in response to a high-fat meal in patients with type 2 diabetes. Arterioscler Thromb Vasc Biol 20, 2039-2044.

Fleischhauer FJ, Yan WD \& Fischell TA (1993) Fish oil improves endothelium-dependent coronary vasodilation in heart transplant recipients. J Am Coll Cardiol 21, 982-989.

Fuentes F, Lopez-Miranda J, Sanchez E, et al. (2001) Mediterranean and low-fat diets improve endothelial function in hypercholesterolemic men. Ann Intern Med 134, 1115-1119.

Gazis A, White DJ, Page SR \& Cockcroft JR (1999) Effect of oral vitamin $\mathrm{E}$ (alpha-tocopherol) supplementation on vascular endothelial function in type 2 diabetes mellitus. Diabetes Med 16, 304-311.

Gilligan DM, Sack MN, Guetta V, Casino PR, Quyyumi AA, Rader DJ, Panza JA \& Cannon RO 3rd (1994) Effect of antioxidant vitamins on low density lipoprotein oxidation and impaired endothelium-dependent vasodilation in patients with hypercholesterolemia. J Am Coll Cardiol 24, 1611-1617.

GISSI-Prevenzione Investigators (1999) Dietary supplementation with $n-3$ polyunsaturated fatty acids and vitamin $\mathrm{E}$ after myocardial infarction: results of the GISSI-Prevenzione trial. Gruppo Italiano per lo Studio della Sopravvivenza nell'Infarto miocardico. Lancet 354, 447-455.

Gokce N, Duffy SJ, Hunter LM, Keaney JF \& Vita JA (2001) Acute hypertriglyceridemia is associated with peripheral vasodilation and increased basal flow in healthy young adults. Am J Cardiol 88, 153-159.

Gokce N, Keaney JF Jr, Hunter LM, Watkins MT, Menzoian JO \& Vita JA (2002) Risk stratification for postoperative cardiovascular events via noninvasive assessment of endothelial function: a prospective study. Circulation 105, 1567-1572.

Gokce N, Keaney JF Jr, Hunter LM, Watkins MT, Nedeljkovic ZS, Menzoian JO \& Vita JA (2003) Predictive value of noninvasively determined endothelial dysfunction for long-term cardiovascular events in patients with peripheral vascular disease. J Am Coll Cardiol 41, 1769-1775.

Goodfellow J, Bellamy MF, Ramsey MW, Jones CJ \& Lewis MJ (2000) Dietary supplementation with marine omega-3 fatty acids improve systemic large artery endothelial function in subjects with hypercholesterolemia. J Am Coll Cardiol 35, 265-270.

Grimble RF, Howell WM, O'Reilly G, et al. (2002) The ability of fish oil to suppress tumor necrosis factor-alpha production by peripheral blood mononuclear cells in healthy men is associated with polymorphisms in genes which influence TNFalpha production. Am J Clin Nutr 76, 454-459.

Haim M, Tanne D, Boyko V, et al. (2002) Soluble intercellular adhesion molecule-1 and long-term risk of acute coronary events in patients with chronic coronary heart disease. Data from the Bezafibrate Infarction Prevention (BIP) Study. $J$ Am Coll Cardiol 39, 1133-1138.

Halcox JP, Schenke WH, Zalos G, et al. (2002) Prognostic value of coronary vascular endothelial dysfunction. Circulation 106, $653-658$

Hamsten A, de Faire U, Walldius G, et al. (1987) Plasminogen activator inhibitor in plasma: risk factor for recurrent myocardial infarction. Lancet 2, 3-9.

Heart Protection Study Collaborative Group (2002) MRC/BHF Heart Protection Study of antioxidant vitamin supplementation in 20,536 high-risk individuals: a randomised placebo-controlled trial. Lancet 360, 23-33.

Heitzer T, Schlinzig T, Krohn K, Meinertz T \& Munzel T (2001) Endothelial dysfunction, oxidative stress, and risk of cardiovascular events in patients with coronary artery disease. Circulation 104, 2673-2678.
Heitzer T, Yla HS, Wild E, Luoma J \& Drexler H (1999) Effect of vitamin $\mathrm{E}$ on endothelial vasodilator function in patients with hypercholesterolemia, chronic smoking or both. J Am Coll Cardiol 33, 499-505.

Hill JM, Zalos G, Halcox JP, et al. (2003) Circulating endothelial progenitor cells, vascular function, and cardiovascular risk. New Engl J Med 348, 593-600.

Hirsch S, Pia De la Maza M, Yanez P, et al. (2002) Hyperhomocysteinemia and endothelial function in young subjects: effects of vitamin supplementation. Clin Cardiol 25, 495-501.

Hozumi T, Eisenberg M, Sugioka K, et al. (2002) Change in coronary flow reserve on transthoracic Doppler echocardiography after a single high-fat meal in young healthy men. Ann Int Med 136, 523-528.

Jacob CO, Fronek Z, Lewis GD, Koo M, Hansen JA \& McDevitt HO (1990) Heritable major histocompatibility complex class IIassociated differences in production of tumor necrosis factor alpha: relevance to genetic predisposition to systemic lupus erythematosus. Proc Natl Acad Sci USA 87, 1233-1237.

Katz DL, Nawaz H, Boukhalil J, et al. (2001) Acute effects of oats and vitamin $\mathrm{E}$ on endothelial responses to ingested fat. Am J Prev Med 20, 124-129.

Khan F, Elherik K, Bolton-Smith C, et al. (2003) The effects of dietary fatty acid supplementation on endothelial function and vascular tone in healthy subjects. Cardiovasc Res 59, 955-962.

Leeson CPM, Hingorani AD, Mullen MJ, et al. (2002a) Glu298Asp endothelial nitric oxide synthase gene polymorphism interacts with environmental and dietary factors to influence endothelial function. Circ Res 90, 1153-1158.

Leeson CPM, Mann A, Kattenhorn M, Deanfield JE, Lucas A \& Muller DPR (2002b) Plasma vitamin E, total antioxidant status and vascular function in young adults. Eur J Clin Invest 32, 889-894.

Leeson CPM, Mann A, Kattenhorn M, Deanfield JE, Lucas A \& Muller DPR (2002c) Relationship between circulating $n-3$ fatty acid concentrations and endothelial function in early adulthood. Eur Heart J 23, 216-222.

Ling L, Zhao SP, Gao M, Zhou QC, Li YL \& Xia B (2002) Vitamin $\mathrm{C}$ preserves endothelial function in patients with coronary heart disease after a high-fat meal. Clin Cardiol 25, 219-224.

London GM \& Cohn JN (2002) Prognostic application of arterial stiffness: task forces. Am J Hyperten 15, 754-758.

McKechnie R, Rubenfire M \& Mosca L (2002) Antioxidant nutrient supplementation and brachial reactivity in patients with coronary artery disease. J Lab Clin Med 139, 133-139.

McGuire W, Hill AV, Allsopp CE, Greenwood BM \& Kwiatkowski D (1994) Variation in the TNF-alpha promoter region associated with susceptibility to cerebral malaria. Nature 371, 508-510.

Mangoni AA, Sherwood RA, Swift CG \& Jackson SH (2002) Folic acid enhances endothelial function and reduces blood pressure in smokers: a randomized controlled trial. J Intern Med 252, 497-503.

Marchesi S, Lupattelli G, Schillaci G, et al. (2000) Impaired flowmediated vasoactivity during post-prandial phase in young healthy men. Atherosclerosis 153, 397-402.

Mensink RP \& Katan MB (1992) Effect of dietary fatty acids on serum lipids and lipoproteins. A meta-analysis of 27 trials. Arterioscler Thromb 12, 911-919.

Modena MG, Bonetti L, Coppi F, Bursi F \& Rossi R (2002) Prognostic role of reversible endothelial dysfunction in hypertensive postmenopausal women. J Am Coll Cardiol 40, 505-510.

Mori TA, Watts GF, Burke V, Hilme E, Puddey IB \& Beilin LJ (2000) Differential effects of eicosapentaenoic acid and docosahexaenoic acid on vascular reactivity of the forearm 
microcirculation in hyperlipidemic, overweight men. Circulation 102, 1264-1269.

Nestel PJ, Shige H, Pomeroy S, Cehun M \& Chin-Dusting J (2001) Post-prandial remnant lipids impair arterial compliance. J Am Coll Cardiol 37, 1929-1935.

Neunteufl T, Heher S, Katzenschlager R, Wolfl G, Kostner K, Maurer G \& Weidinger F (2000) Late prognostic value of flow-mediated dilation in the brachial artery of patients with chest pain. Am J Cardiol 86, 207-210.

O'Grady HL, Leahy A, McCormick PH, Fitzgerald P, Kelly CK \& Bouchier-Hayes DJ (2002) Oral folic acid improves endothelial dysfunction in cigarette smokers. J Surg Res 106, 342-345.

Ong PJ, Dean TS, Hayward CS, Della Monica PL, Sanders TA \& Collins P (1999) Effect of fat and carbohydrate consumption on endothelial function. Lancet 354, 2134.

Pearson TA, Mensah GA, Alexander RW, et al. (2003) Markers of inflammation and cardiovascular disease: application to clinical and public health practice: A statement for healthcare professionals from the Centers for Disease Control and Prevention and the American Heart Association. Circulation 107, 499-511.

Perez-Jimenez F, Castro P, Lopez-Miranda J, et al. (1999) Circulating levels of endothelial function are modulated by dietary monounsaturated fat. Atherosclerosis 145, 351-358.

Perticone F, Ceravolo R, Pujia A, et al. (2001) Prognostic significance of endothelial dysfunction in hypertensive patients. Circulation 104, 191-196.

Plotnick GD, Corretti MC \& Vogel RA (1997) Effect of antioxidant vitamins on the transient impairment of endotheliumdependent brachial artery vasoactivity following a single high-fat meal. $J$ Am Med Assoc 278, 1682-1686.

Plotnick GD, Corretti MC, Vogel RA, Hesslink R Jr \& Wise JA (2003) Effect of supplemental phytonutrients on impairment of the flow-mediated brachialartery vasoactivity after a single high-fat meal. J Am Coll Cardiol 41, 1744-1749.

Pullin CH, Ashfield-Watt PA, Burr ML, et al. (2001) Optimization of dietary folate or low-dose folic acid supplements lower homocysteine but do not enhance endothelial function in healthy adults, irrespective of the methylenetetrahydrofolate reductase (C677T) genotype. J Am Coll Cardiol 38, 1799-1805.

Raitakari OT, Lai N, Griffiths K, McCredie R, Sullivan D \& Celermajer DS (2000) Enhanced peripheral vasodilation in humans after a fatty meal. J Am Coll Cardiol 36, 417-422.

Ramsay JE, Ferrell WR, Greer IA \& Sattar N (2002) Factors critical to iontophoretic assessment of vascular reactivity: implications for clinical studies of endothelial dysfunction. J Cardiovasc Pharmacol 39, 9-17.

Ridker PM, Hennekens CH, Roitman-Johnson B, Stampfer MJ \& Allen J (1998) Plasma concentration of soluble intercellular adhesion molecule 1 and risks of future myocardial infarction in apparently healthy men. Lancet 351, 88-92.

Roche HM, Zampelas A, Knapper JM, et al. (1998) Effect of longterm olive oil dietary intervention on postprandial triacylglycerol and factor VII metabolism. Am J Clin Nutr 68, 552-560.

Ross R (1999) Atherosclerosis is an inflammatory disease. Am Heart J 138, S419-S420.

Safar ME, Henry O \& Meaume S (2002) Aortic pulse wave velocity: an independent marker of cardiovascular risk. Am J Geriatr Cardiol 11, 295-298.

Schaaf BM, Seitzer U, Pravica V, Aries SP \& Zabel P (2001) Tumor necrosis factor-alpha-308 promoter gene polymorphism and increased tumor necrosis factor serum bioactivity in farmer's lung patients. Am J Respir Crit Care Med 163, $379-382$.

Schächinger V, Britten MB \& Zeiher AM (2000) Prognostic impact of coronary vasodilator dysfunction on adverse long-term outcome of coronary heart disease. Circulation 101, 1899-1906.

Schindler TH, Hornig B, Buser PT, Olschewski M, Magosaki N, Pfisterer M, Nitzsche EU, Solzbach U \& Just H (2003) Prognostic value of abnormal vasoreactivity of epicardial coronary arteries to sympathetic stimulation in patients with normal coronary angiograms. Arterioscler Thromb Vasc Biol 23, 495-501.

Sejda T, Kovar J, Pitha J, Cifkova R, Svandova E \& Poledne R (2002) The effect of an acute fat load on endothelial function after different dietary regimens in young healthy volunteers. Physiol Res 51, 99-105.

Shimasaki Y, Yasue H, Yoshimura M, et al. (1998) Association of the missense Glu298Asp variant of the endothelial nitric oxide synthase gene with myocardial infarction. $\mathrm{J} \mathrm{Am} \mathrm{Coll}$ Cardiol 31, 1506-1510.

Stein JH, Keevil JG, Wiebe DA, Aeschlimann S \& Folts JD (1999) Purple grape juice improves endothelial function and reduces the susceptibility of LDL cholesterol to oxidation in patients with coronary artery disease. Circulation 100, $1050-1055$.

Stuber F, Petersen M, Bokelmann F \& Schade U (1996) A genomic polymorphism within the tumor necrosis factor locus influences plasma tumor necrosis factor-alpha concentrations and outcome of patients with severe sepsis. Crit Care Med 24, $381-384$.

Suwaidi JA, Hamasaki S, Higano ST, Nishimura RA, Holmes DR Jr \& Lerman A (2000) Long-term follow-up of patients with mild coronary artery disease and endothelial dysfunction. Circulation 101, 948-954.

Thies F, Garry JMC, Yaqoob P, et al. (2003) Association of $n-3$ polyunsaturated fatty acids with stability of atherosclerotic plaques: a randomised controlled trial. Lancet 361, 477-485.

Thogersen AM, Jansson J, Boman K, Nilsson TK \& Weinehall L (1998) High plasminogen activator inhibitor and tissue plasminogen activator levels in plasma precede a first acute myocardial infarction in both men and women: evidence for the fibrinolytic system as an independent primary risk factor. Circulation 98, 2241-2247.

Thompson SG, Kienast J, Pyke SD, Haverkate F \& van de Loo JCW (1995) Hemostatic factors and the risk of myocardial infarction or sudden death in patients with angina pectoris. New Engl J Med 332, 635-641.

Title LM, Cummings PM, Giddens K, Genest JJ Jr \& Nassar BA (2000) Effect of folic acid and antioxidant vitamins on endothelial dysfunction in patients with coronary artery disease. $J$ Am Coll Cardiol 36, 758-765.

Vita JA (2002) Nitric oxide-dependent vasodilation in human subjects. Methods Enzymol 359, 186-200.

Vita JA \& Keaney JF Jr (2002) Endothelial function: a barometer for cardiovascular risk? Circulation 106, 640-642.

Vogel RA, Corretti MC \& Plotnick GD (1997) Effect of a single high-fat meal on endothelial function in healthy subjects. Am J Cardiol 79, 350-354.

Vogel RA, Corretti MC \& Plotnick GD (2000) The postprandial effect of components of the Mediterranean diet on endothelial function. J Am Coll Cardiol 36, 1455-1460.

Willems FF, Aengevaeren WR, Boers GH, Blom HJ \& Verheugt FW (2002) Coronary endothelial function in hyperhomocysteinemia: improvement after treatment with folic acid and cobala$\mathrm{min}$ in patients with coronary artery disease. $\mathrm{J} \mathrm{Am} \mathrm{Coll} \mathrm{Cardiol}$ 40, 766-772.

Williams MJ, Sutherland WH, McCormick MP, de Jong SA, Walker RJ \& Wilkins GT (1999) Impaired endothelial function following a meal rich in used cooking fat. $\mathrm{J}$ Am Coll Cardiol 33, $1050-1055$. 
Williams MJ, Sutherland WH, McCormick MP, Yeoman D, de Jong SA \& Walker RJ (2001) Normal endothelial function after meals rich in olive or safflower oil previously used for deep frying. Nutr Metab Cardiovasc Dis 11, 147-152.

Wiman B, Andersson T, Hallqvist J, Reuterwall C, Ahlbom A \& deFaire U (2000) Plasma levels of tissue plasminogen activator/plasminogen activator inhibitor-1 complex and von Willebrand factor are significant risk markers for recurrent myocardial infarction in the Stockholm Heart Epidemiology Program (SHEEP) study. Arterioscler Thromb Vasc Biol 20, 2019-2023.
Wolever TM \& Mehling C (2003) Long-term effect of varying the source or amount of dietary carbohydrate on postprandial plasma glucose, insulin, triacylglycerol, and free fatty acid concentrations in subjects with impaired glucose tolerance. Am J Clin Nutr 77, 612-621.

Yusuf S, Dagenais G, Pogue J, Bosch J \& Sleight P (2000) Vitamin E supplementation and cardiovascular events in high-risk patients. The Heart Outcomes Prevention Evaluation Study Investigators. New Engl J Med 342, 154-160.

Zock PL, Katan MB \& Mensink RP (1995) Dietary trans fatty acids and lipoprotein cholesterol. Am J Clin Nutr 61, 617. 